\title{
Putting measures of individual well-being to use for ex-ante policy evaluation
}

\author{
H. Xavier Jara ${ }^{1} \cdot$ Erik Schokkaert $^{2,3}$
}

Published online: 20 December 2017

(C) The Author(s) 2017. This article is an open access publication

\begin{abstract}
Most studies using microsimulation techniques have considered the effect of potential reforms on the income distribution. However, it has become increasingly recognized, both at the academic and political level, that focusing purely on income provides a limited picture of social progress. We illustrate how ex-ante policy evaluation can be performed in terms of richer concepts of individual well-being, such as subjective life satisfaction and equivalent incomes. Our analysis makes use of EUROMOD, the EU-wide tax-benefit microsimulation model, along with 2013 EU-SILC data for Sweden, which for the first time provides information on life satisfaction. Our results show that the effect of potential reforms varies widely depending on the well-being concept used in the evaluation. We discuss the normative questions that are raised by this finding.
\end{abstract}

Keywords Disposable income $\cdot$ Satisfaction $\cdot$ Equivalent income $\cdot$ Microsimulation

Electronic supplementary material The online version of this article (https://doi.org/10.1007/s10888-017-9370-x) contains supplementary material, which is available to authorized users.

Erik Schokkaert

erik.schokkaert@kuleuven.be

H. Xavier Jara

hxjara@essex.ac.uk

1 Institute for Social and Economic Research, University of Essex, Colchester, UK

2 Department of Economics, Katholieke Universiteit Leuven, Leuven, Belgium

3 CORE (Universite Catholique de Louvain), Louvain-la-Neuve, Belgium 


\section{Introduction}

Since the pioneering work of Atkinson et al. (1983), tax-benefit microsimulation models have proved to be a powerful tool for ex-ante evaluation of tax-benefit policy reforms. Until now most applications have considered the effect of potential reforms on the income distribution only. Yet it has become increasingly recognized, both at the academic and political level, that such an exclusive focus on income provides only a limited picture of social progress (see, e.g., the report by Stiglitz et al. 2009) and that it is also necessary to consider a larger set of social indicators for the evaluation of poverty and social inclusion (see, e.g., Atkinson et al., 2002). In addition to income, life dimensions such as health, employment, leisure, housing and environmental quality are also highly valued as determinants of a good life, and should be taken into account in policy evaluation. The aim of this paper is to illustrate how microsimulation can be used for the ex-ante evaluation of policy reforms within such a richer evaluative framework.

The obvious first step in such an evaluation is the analysis of the effects of the policy on the different dimensions of life that are relevant to individual well-being. In this exercise, it is important to take cross-effects into account. As an example, a larger income may have an effect on health, while a better health may influence the earning capacity of individuals. If one aims at clear-cut policy prescriptions, the next step is the aggregation of the different life dimensions into a single indicator of individual well-being. The choice of such a single indicator is driven by normative considerations, about which there is no consensus in the literature. ${ }^{1}$ We will therefore show the results for two different "aggregators": life satisfaction and equivalent income. In Section 2 we briefly sketch the normative intuitions behind these concepts and explain which empirical information is needed for their implementation.

Our empirical work is based on the SILC 2013 data for Sweden. SILC 2013 contains detailed information on income components, employment, self-assessed health, housing conditions and, for the first time, a module on subjective life satisfaction and emotions. We use the EU-wide tax-benefit model EUROMOD to calculate household disposable income. In Section 3 we sketch a picture of the distribution of well-being in Sweden for the three welfare concepts used in this paper (disposable income, life satisfaction, equivalent income), and we show that there are significant differences between these three views. This offers the basis from which we proceed to evaluate the effects of four counterfactual tax-benefit policy reforms: an additional payment for recipients of social assistance, an increase in the basic amount of child benefit, an additional payment of housing allowance for pensioners, and an improvement in the quality of low-quality housing. In each case, budget neutrality is achieved by increasing the top rate of the government income tax. We analyze the effects of these policies in Section 4. Again, the choice of well-being measure has a significant impact on the evaluation results. Note that our fourth reform only results in losers if we focus exclusively on disposable income, since the gainers see the quality of their houses improved but do not receive any income transfer. Section 5 concludes.

Our paper conveys two messages. First, it highlights the feasibility of evaluating (ex-ante) the effect of policy reforms not only on income but also on other well-being indicators. Nonmonetary policies may have an important effect on well-being, and they cannot be analyzed if policy evaluation is restricted to an assessment in terms of income. Second, it shows the importance of comparing different well-being indicators to assess the potential effect of a

\footnotetext{
${ }^{1}$ An overview of the debate and a critical discussion of the different possibilities can be found in Fleurbaey and Blanchet (2013) and Decancq et al. (2015a).
} 
policy reform. Careful policy analysis requires an explicit discussion of the underlying value judgments (Atkinson 2011).

\section{Measures of individual well-being}

In this section we describe our three measures of individual well-being (disposable income, life satisfaction and equivalent income) and discuss how they can be implemented empirically for ex-ante policy evaluation.

\subsection{Income and other life dimensions}

The vast majority of studies assessing the effects of tax-benefit policy reforms have opted for disposable income as a measure of individual well-being. Let $y_{i}$ represent disposable income of individual $i, \omega_{i}$ market income and $z_{i}$ a vector of individual and household characteristics that are relevant within the tax-benefit regulations of the country. Then disposable income is given by: ${ }^{2}$

$$
y_{i}=d\left(\omega_{i}, z_{i}, p_{y}\right),
$$

where $d($.) represents the tax-benefit function transforming market income and individual and household characteristics into disposable income, and $p_{y}$ is a set of parameters of the tax-benefit system (e.g. maximum benefit amounts, minimum thresholds for social insurance contributions, level of tax bands, etc.). Provided that detailed information about market incomes, individual and household characteristics, and the parameters (i.e. the rules) of taxbenefit policies in a country is available, tax-benefit microsimulation models can be used to calculate the disposable income of all individuals in the sample.

Denote by $l_{i}$ the other life dimensions (such as health, quality of housing, employment, etc.) that are also important determinants of the well-being of individual $i$. Analogously to Eq. 1 , we can write that $l_{i j}$, the level of life dimension $j$ reached by individual $i$, is determined by his income $y_{i}$, the quality of other life dimensions $l_{i(-j)}$, a vector of policy parameters $p_{l j}$ and relevant individual characteristics $z_{i}:{ }^{3}$

$$
l_{i j}=l\left(y_{i}, l_{i(-j)}, z_{i}, p_{l j}, \epsilon_{i j}\right)
$$

with $\epsilon_{i j}$ a disturbance term. If the necessary information is available, Eq. 2 can be estimated. It is then also possible to simulate the effects of changes in $p_{l j}$ on the value $l_{i j}$, reached by individual $i$. Note that changes in $p_{y}$ may affect the non-income life dimensions if $y_{i}$ has a significant effect in Eq. 2.

\subsection{Life satisfaction}

In some cases, e.g. when we only want to calculate the value of multidimensional inequality or poverty (Atkinson 2003; Aaberge and Brandolini 2015), it is sufficient to collect

\footnotetext{
${ }^{2}$ We omit time subscripts, since our empirical work will only make use of cross-section data.

${ }^{3}$ While there will be some overlap, the individual characteristics that are relevant for the different life dimensions do not coincide and are not identical with the individual characteristics that play a role in the tax-benefit system. To simplify the notation, we still use the same symbol $z_{i}$ in Eqs. 1 and 2. One way to interpret this is to see $z_{i}$ as a vector containing all individual characteristics, while keeping in mind that only a subset of these characteristics will have a significant effect on each of the separate dimensions, with the others having zero effect.
} 
information on the vector $\left(y_{i}, l_{i}\right)$. However, for a full welfare evaluation it is desirable to aggregate these different dimensions into one overall measure of individual well-being. ${ }^{4}$ One possibility for doing this is to use a set of objective weights, the same for all individuals. Such an objective approach disregards the fact that different individuals may have different opinions about what is important in life, i.e. that they may have different preferences. The economic tradition takes the position that such differences in individual preferences should be respected. We will follow that tradition in this paper and restrict ourselves to measures of well-being that respect preference heterogeneity. ${ }^{5}$

In recent years, subjective well-being measures, such as happiness and life satisfaction measured with large representative surveys, have become increasingly popular in this regard, and some authors (e.g. Layard 2005; O'Donnell and Oswald 2015) have advocated the use of these indicators in policy evaluation. ${ }^{6}$ Numerous studies have shown that non-monetary life dimensions, in addition to income, are important determinants of life satisfaction. We can therefore represent life satisfaction $S_{i}$ of individual $i$ as a function

$$
S_{i}=S_{i}\left(y_{i}, l_{i}\right) \text {. }
$$

Equation 3 can be estimated. After simulating the effects of a policy measure on $\left(y_{i}, l_{i}\right)$ (based on Eqs. 1-2), we can use the estimated version of Eq. 3 to also simulate the effect on individual life satisfaction.

Note that Eq. 3 makes explicit that the life satisfaction function $S_{i}($.$) is individual-$ specific. For the normative interpretation of using life satisfaction as a measure of well-being, it is useful to distinguish between two causes of these interindividual differences. First, as mentioned before, individuals may have different preferences, i.e. they may differ in the relative importance they attach to different life dimensions. Second, even if two individuals have identical preferences and the same bundle $(y, l)$, they may still experience a different level of life satisfaction due to different scalings of satisfaction. In economic jargon, the former explanation leads to differences in marginal rates of substitution, the latter refers to the cardinalization of the satisfaction function.

We have already argued that in a liberal society it is a natural assumption to respect differences in satisfaction that reflect differences in preferences, i.e. to consider that a person whose individual outcomes do not match his preferences is indeed worse off. Being unemployed is worse for someone who attaches a large importance to the social integration that comes with having a job.

It is much less clear, however, as to whether we should also respect scaling differences. These differences mainly reflect individual aspirations and expectations. Let us consider two examples. Suppose that Ann and Beth are in exactly the same objective situation: they have the same income, the same health, the same job situation, etc. Ann comes from a rich family

\footnotetext{
${ }^{4}$ An alternative approach, pioneered by Atkinson and Bourguignon (1982), is to look for multidimensional dominance results.

${ }^{5}$ Within economics the most influential "objective" approach is the capability approach, as defended by Sen (1985) and Nussbaum (2000). A critical discussion of this approach can be found in Decancq et al. (2015a) and Fleurbaey and Blanchet (2013). Decancq et al. (2016) show how preference differences can be integrated into empirical applications of the capability approach.

${ }^{6}$ In principle, happiness and life satisfaction are two different concepts. Yet, the answers to both measures in large surveys are strongly correlated. Some authors claim that this suggests that they both measure the same underlying concept ("utility"?), others however argue that it is rather the result of an ambiguous formulation of the questions (see Fleurbaey and Blanchet (2013), for an overview of this discussion). We will use in this paper only the results for the more cognitive concept of life satisfaction.
} 
and is used to an opulent life, while Beth has poor parents and her actual situation is much better than what she had expected in her childhood. As a result, Ann has a lower level of life satisfaction than Beth. Should we then try to compensate Ann for her "misfortune" of being born into a rich family? Or, consider two individuals John and Jim, who both have a strong preference for not being disabled. Jim has an accident and loses a limb. However, after some time he adapts to his new situation: he still would prefer to be able-bodied but his satisfaction level returns to what it was before the accident. Does this imply that we should not take into account his loss of a limb in the evaluation of his well-being? In fact, does this mean that society in general should not care very much about individuals losing a limb? ${ }^{7}$ Sen (1985, p. 21) has pointed out that subjective well-being measures may suffer from what he calls "physical-condition neglect": "A person who is ill-fed, undernourished, unsheltered and ill can still be high up in the scale of happiness or desire-fulfillment if he or she has learned to have 'realistic' desires and to take pleasure in small mercies." If this is considered a problem, one must look for a measure of individual well-being that does respect differences in individual preferences but does not suffer from physical-condition neglect. One possible candidate is equivalent income (Fleurbaey and Blanchet 2013; Fleurbaey and Maniquet 2011; Decancq et al. 2015a, b; Schokkaert et al. 2011).

\subsection{Equivalent income}

Choose reference values for all the non-income dimensions and denote them by $\bar{l}$. The equivalent income of individual $i$, written as $y_{i}^{*}$, is then implicitly defined by the expression

$$
\left(y_{i}^{*}, \bar{l}\right) I_{i}\left(y_{i}, l_{i}\right),
$$

where $I_{i}$ is the indifference relation of individual $i$. In words, equivalent income is the hypothetical income that, combined with the reference value for all non-income dimensions, would place the individuals in a situation that they find equally good as their actual situation. Let us explain its normative intuition using Fig. 1, in which we depict a situation with two life dimensions: income and health. The indifference curves through A and B represent the preferences of two individuals Ann and Beth respectively. We assume that society agrees that there is some level of health seen as "perfect".

First consider a situation where Ann and Beth are both in X: they have the same income and the same health level. If we want to respect individual preferences, it does not necessarily follow from their identical objective outcomes that they also enjoy the same level of well-being: in X the indifference curve of Ann is steeper than that of Beth, showing that she is more concerned about being (un)healthy. It is therefore natural to accept that Ann is worse off than Beth. In general, preferences do matter. There is, however, one situation for which it can be argued that preference differences should not matter, and this is when both Ann and Beth are perfectly healthy. In this situation it would be very strange to claim that either of the two has a lower well-being level because she cares less (or more?) about her health. This means that when two individuals are both in perfect health, we can compare their well-being on the basis of their incomes, irrespective of their preferences. Combining this insight with respect for individual preferences allows us to rank all possible situations. Assume that Ann is in A and Beth in B. According to their own preferences, Ann is equally

\footnotetext{
${ }^{7}$ This example is inspired by the empirical work of Loewenstein and Ubel (2008). The literature documents many spectacular cases of adaptation. An extreme example is described in Bruno et al. (), who show that even patients with locked-in syndrome can recover a high degree of subjective life satisfaction.
} 


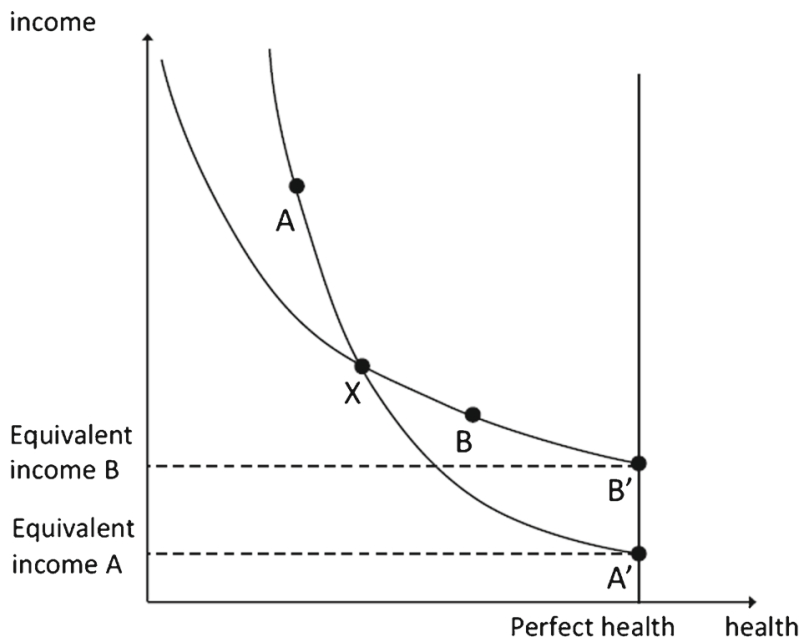

Fig. 1 Equivalent income

well-off in A and A', and Beth is equally well-off in B and B'. Yet, in A' and B' they are both in perfect health. Given that we then can evaluate the lives A' and B' on the basis of their incomes, we can also evaluate $\mathrm{A}$ and $\mathrm{B}$ on the basis of these incomes. The well-being of Ann (Beth) in A (B) can then be measured by the equivalent income A (B) in Fig. 1.

The criterion to set the reference values for the non-income dimensions is therefore that at these reference values preference differences should not matter for measuring well-being. If preferences can be assumed to be monotonic in a life dimension that has a natural upper bound (as is the case for health), this upper bound is a natural choice for the reference value. If the non-income dimension does not have an upper bound (e.g. quality of housing), one may use a value that is close to the maximum of the observed distribution. ${ }^{8}$

It is clear that the equivalent income measure indeed respects individual preferences. It does not suffer from "physical-condition neglect". If two individuals hold the same preferences, the one on the higher indifference curve will always have a larger equivalent income, independent of the (possibly individual-specific) scaling of subjective satisfaction. Despite the fact that it is expressed in monetary terms (which has some practical advantages when it comes to measurement), it is an encompassing measure of well-being taking into account the well-being loss that follows from not achieving the reference values for the non-income dimensions. In fact, in Fig. 1 Ann in A has a larger monetary income than Beth in B, but her equivalent income is lower because her health is worse. The well-being loss is individualspecific as it does depend on the individual's own preferences. Remember that the equivalent incomes of Ann and Beth would be different if they were both in situation X.

Implementation of the equivalent income measure requires information on individual preferences. In this paper, we follow Decancq et al. (2015b, 2017) and Schokkaert et al. (2011) and retrieve information about individual preferences from life satisfaction regressions. ${ }^{9}$ This method is explained in the following subsection.

\footnotetext{
${ }^{8}$ With non-monotonic preferences the most natural choice is the individual-specific best value for that dimension - see Fleurbaey and Blanchet (2013) and Decancq et al. (2015b).

${ }^{9}$ Two other methods have been used in the literature to derive preference information for the calculation of equivalent incomes. Bargain et al. (2013) and Decoster and Haan (2015) use a revealed preferences
} 


\subsection{Toward operational implementation: evaluating the effect of policy changes}

As already mentioned before, we need a tax-benefit microsimulation model for the empirical implementation of Eq. 1. We furthermore must choose a specific functional form for Eqs. 2 and 3. For the former we will use a simple linear specification. The latter, however, is more important since we also want to use its estimates to calculate equivalent incomes. It is therefore necessary to be able to distinguish differences in preferences from differences in aspirations and expectations. A simple way to do this is to specify the life satisfaction regression (3) as

$$
S_{i}=\alpha+\pi \ln \left(y_{i}\right)+\left(\beta+\gamma^{\prime} z_{i}\right)^{\prime} l_{i}+\delta^{\prime} z_{i}+\varepsilon_{i},
$$

where $l_{i}$ and $z_{i}$ are again the non-income dimensions and personal characteristics (e.g. gender, age, etc.) respectively, $(\alpha, \pi, \beta, \gamma, \delta)$ are coefficients to be estimated and $\varepsilon_{i}$ is a disturbance term. Equation 5 is a natural extension of the most common specification in the empirical happiness literature. Differences in preferences are modeled through the interaction effects between $z_{i}$ and $l_{i}$. As an example, the marginal rate of substitution of individual $i$ between $y_{i}$ and $l_{i j}$ is given by

$$
\operatorname{MRS}_{i}\left(y_{i}, l_{i j}\right)=\frac{\left(\beta+\gamma^{\prime} z_{i}\right) y_{i}}{\pi} .
$$

The direct effects of $z_{i}$ on life satisfaction, parameterized with $\delta$, and the idiosyncratic disturbance term $\varepsilon_{i}$ are interpreted as capturing aspirations and expectations. They do not affect the marginal rates of substitution, i.e. the slope of the indifference curves, but they do affect the cardinalization of life satisfaction.

Starting from Eq. 5, we can now implement definition (4) as:

$$
S_{i}=\alpha+\pi \ln y_{i}+\left(\beta+\gamma^{\prime} z_{i}\right)^{\prime} l_{i}+\delta^{\prime} z_{i}+\varepsilon_{i}=\alpha+\pi \ln y_{i}^{*}+\left(\beta+\gamma^{\prime} z_{i}\right)^{\prime} \bar{l}+\delta^{\prime} z_{i}+\varepsilon_{i},
$$

which immediately yields

$$
y_{i}^{*}=y_{i} \exp \left[\left(\frac{\beta+\gamma^{\prime} z_{i}}{\pi}\right)^{\prime}\left(l_{i}-\bar{l}\right)\right] .
$$

The estimates of the coefficients in Eq. 5 can now be used to calculate equivalent incomes. Differences in preferences are taken up in this expression through the differences in the marginal rates of substitution (compare (7) and (6)). Differences in scaling (as captured by the terms $\left.\delta^{\prime} z_{i}+\varepsilon_{i}\right)$ do not appear in Eq. 7 .

We now have all the information for the ex-ante evaluation of policy reforms in terms of individual well-being. Consider for instance that we would like to evaluate the effect of changing the parameters $p_{y}$ of the tax-benefit system to a set of hypothetical values $p_{y}^{C}$. The disposable income $y_{i}^{C}$ of individual $i$ under the counterfactual scenario $C$ can be simulated with the tax-benefit microsimulation model:

$$
y_{i}^{C}=d\left(\omega_{i}, x_{i}, p_{y}^{C}\right) .
$$

We then introduce $y_{i}^{C}$ into the estimated set of Eqs. 2 to get an estimate $\hat{l}_{i}^{C}$ of the non-income dimensions. The effect of the counterfactual policy reform $C$ on life satisfaction can be assessed by comparing the distribution of predicted life satisfaction $\hat{S}_{i}$ (obtained using the

approach to income-leisure preferences with random utility models of labor supply. Fleurbaey et al. (2013) and Schokkaert et al. (2013) use contingent valuation techniques as part of a stated preference approach. 
estimated coefficients in Eq. 5) with the distribution of $\hat{S_{i}^{C}}$, where $\hat{S_{i}^{C}}$ represents predicted life satisfaction with disposable income $y_{i}$ and non-income dimensions $l_{i}$ replaced by $y_{i}^{C}$ and $\hat{l_{i}^{C}}$, respectively. A similar method applies to equivalent incomes, where the estimated equivalent incomes of the base situation $\hat{y}_{i}^{*}$ can be compared with the estimated equivalent incomes $y_{i}^{\hat{C}} *$ in the counterfactual scenario.

\section{Data and estimation of well-being in Sweden}

\subsection{The data: EUROMOD and EU-SILC}

In order to calculate household disposable income under different policy reform scenarios, we use EUROMOD, the EU tax-benefit microsimulation model. EUROMOD simulates cash benefit entitlements and direct personal tax and social insurance contribution liabilities on the basis of the tax-benefit rules in place in each of the $28 \mathrm{EU}$ Member States. ${ }^{10}$ The underlying micro-data used for the simulations in EUROMOD is EU-SILC, which contains detailed information on different income sources as well as household and individual characteristics.

In addition to detailed income information, our analysis requires information on overall life satisfaction and on the different life dimensions that individuals consider important. We use EU-SILC 2013, which for the first time incorporates information about life satisfaction and about emotions (feelings of happiness, depression, etc.). Our analysis is restricted to Sweden because EU-SILC 2013 is not one of the waves used as input data in EUROMOD. For this reason, the original EU-SILC 2013 data for Sweden has been updated and modified according to the requirements for EUROMOD. ${ }^{11}$ EU-SILC 2013 contains 15,143 observations for Sweden. Life satisfaction information is available for individuals aged 16 years or older and is measured on an 11-point scale ranging from 0 ("not satisfied at all") to 10 ("fully satisfied"). Four life dimensions are considered in the estimation: income, health, being unemployed and housing quality. In our estimations, income is defined as the logarithm of household disposable income, equivalized with the modified OECD scale. Health is measured by self-assessed health, which is a categorical variable measured on a 5-point scale ranging from 1 ("poor health") to 5 ("excellent health"). The unemployment dummy takes on the value of 1 if the person is unemployed according to his/her current reported labor market status. Housing quality is derived from a hedonic price equation, where imputed rent is regressed on a series of housing characteristics, such as dwelling type, number of rooms in the dwelling, availability of bath, toilet and telephone, and the presence of problems such as darkness, heat, noise, pollution and crime. Housing quality is the predicted value of this hedonic regression after correcting for household size and regional price

\footnotetext{
${ }^{10}$ See Sutherland and Figari (2013) for more information.

${ }^{11}$ The income information in EU-SILC 2013 refers to incomes in 2012, while life satisfaction, household characteristics, and labor market information refer to 2013. For this reason, EUROMOD is used in a first instance to simulate disposable income in 2013, which is then used in the life satisfaction regressions and to calculate equivalent incomes. Additionally, in order to account for the fact that people might have changed labor market status between the income reference period and the survey reference period, we exclude people for whom the current labor market information does not match the specific information about months in work, unemployment, or other labor market status in the income reference period. Our results are not affected by these choices.
} 
differences. ${ }^{12}$ Our analysis uses the observations for which all necessary variables have non-missing information. This leaves us with a sample of 5,336 observations. Descriptive statistics are presented in Table 8 in the Online Appendix.

\subsection{Calculation of equivalent incomes on the basis of life satisfaction data}

The calculation of equivalent incomes starts with the estimation of life satisfaction equation (5). The estimates obtained with our data are given in Table 1. To model intergroup differences in preferences, the non-monetary life dimensions, health, unemployment status and housing quality, are interacted with dummies for being male, having a higher education degree and being aged 40 or more. We also introduce into the policy analysis the indirect effects of policy changes through their effects on health. Estimates of Eq. 2 for health are shown in Table 2.

Two methodological points should be noted. First, because we are only able to use a single cross-section of EU-SILC, we cannot implement panel methods to account for unobserved individual heterogeneity in the life satisfaction and health regressions. Failure to control for individual-specific time-invariant characteristics might result in a bias in the estimated coefficients (Ferrer-i-Carbonell and Frijters 2004). A second best solution, in the case of a lack of panel data, is to use information on personality traits. Unfortunately, EU-SILC does not contain this information either. Therefore, we use information about self-rated affects or emotions available in EU-SILC 2013, as a sort of third best solution to control for individual-specific time-invariant characteristics. More specifically, respondents had to indicate whether they felt over the past four weeks "very nervous", "down in the dumps", "calm and peaceful", and "downhearted or depressed". Responses are recorded as a categorical variable measured on a 5-point scale ranging from 1 ("All of the time") to 5 ("None of the time"). We have reversed the scoring so that higher values reflect that the respondent has felt these emotions more frequently.

Secondly, there is an issue of potential endogeneity of self-assessed health in the life satisfaction equation, and even more so since these are both self-reported subjective variables. Table 1 therefore shows the results of 2SLS-regressions. Table 2 and Tables 10-12 in the Online Appendix present results for the first stage estimation of health-related variables. ${ }^{13}$

The estimation results for the life satisfaction (Table 1) are in line with previous findings in the literature. The left column (Model 1) shows the results when emotions are not included as regressors while the right column (Model 2) includes the four emotion variables as controls. Income, defined as the logarithm of equivalized household disposable income, has a positive and significant effect on life satisfaction. The three other life dimensions considered in our analysis, self-assessed health, unemployment status and housing quality, also produce the expected effects on life satisfaction, although housing quality is not significant in model 2. Note that the magnitude of the coefficients of income and other life dimensions decreases under model 2 with the introduction of the emotion variables. This is in line with the idea that not accounting for factors related to personality traits might bias the estimates of the life satisfaction regressions. However, since the estimates of all coefficients go down, the effect on the marginal rates of substitution is smaller than the effect on life

\footnotetext{
${ }^{12}$ The method is similar to that used by Decancq et al. (2015b). Detailed results are available upon request from the authors.

${ }^{13}$ Table 9 in the Appendix shows that the 2SLS-estimates are broadly consistent with those that are obtained with OLS or ordered logit models. The estimated effect of health on life satisfaction is smaller with 2SLS.
} 
Table 1 Life Satisfaction Regressions (2SLS)

\begin{tabular}{|c|c|c|}
\hline & Model 1 & Model 2 \\
\hline Disposable Income (log) & $0.142^{* * *}(0.044)$ & $0.081^{* *}(0.039)$ \\
\hline Self-reported health & $0.669^{* * *}(0.085)$ & $0.247^{* * *}(0.082)$ \\
\hline Unemployed & $-0.870^{* * *}(0.189)$ & $-0.621^{* * *}(0.170)$ \\
\hline Housing (in 1000SEK) & $0.129^{* * *}(0.048)$ & $0.036(0.043)$ \\
\hline Health x Male & $0.114(0.085)$ & $0.143^{*}(0.077)$ \\
\hline Health $x$ High. Education & $0.018(0.104)$ & $0.095(0.093)$ \\
\hline Health x Age over 40 & $0.145^{* *}(0.067)$ & $0.041(0.059)$ \\
\hline Unempl. x Male & $0.337^{*}(0.203)$ & $0.326^{*}(0.182)$ \\
\hline Unempl. x High. Education & $-0.504 *(0.282)$ & $-0.328(0.253)$ \\
\hline Unempl. x Age over 40 & $0.117(0.202)$ & $0.196(0.181)$ \\
\hline Housing x Male & $0.012(0.028)$ & $0.021(0.025)$ \\
\hline Housing $\mathrm{x}$ High. Education & $-0.037(0.030)$ & $-0.018(0.027)$ \\
\hline Housing x Age over 40 & $-0.112^{*}(0.059)$ & $-0.015(0.052)$ \\
\hline Male & $-0.602^{*}(0.364)$ & $-0.908^{* * *}(0.327)$ \\
\hline Age & $-0.055^{* * *}(0.011)$ & $-0.053^{* * *}(0.010)$ \\
\hline Age squared/100 & $0.060^{* * *}(0.009)$ & $0.049^{* * *}(0.008)$ \\
\hline Married & $0.465^{* * *}(0.055)$ & $0.433^{* * *}(0.050)$ \\
\hline Separated & $-0.397^{* *}(0.183)$ & $-0.117(0.165)$ \\
\hline Divorced & $-0.031(0.075)$ & $-0.009(0.067)$ \\
\hline Widow & $0.178^{*}(0.104)$ & $0.214^{* *}(0.093)$ \\
\hline Children 0-15 & $0.147^{* * *}(0.051)$ & $0.152^{* * *}(0.046)$ \\
\hline Non-Swede & $-0.083(0.100)$ & $0.042(0.089)$ \\
\hline Higher Education & $-0.120(0.444)$ & $-0.471(0.398)$ \\
\hline South Sweden & $0.110^{* *}(0.043)$ & $0.096^{* *}(0.038)$ \\
\hline North Sweden & $0.236^{* * *}(0.057)$ & $0.175^{* * *}(0.051)$ \\
\hline Down in the dumps & & $-0.195^{* * *}(0.032)$ \\
\hline Calm & & $0.341^{* * *}(0.028)$ \\
\hline Nervous & & $-0.130^{* * *}(0.025)$ \\
\hline Downhearted & & $-0.345^{* * *}(0.029)$ \\
\hline _cons & $4.153^{* * *}(0.572)$ & $6.808^{* * *}(0.566)$ \\
\hline$N$ & 5336 & 5336 \\
\hline$R^{2}$ & 0.203 & 0.361 \\
\hline
\end{tabular}

Standard errors in parentheses

${ }^{*} p<0.10,{ }^{* *} p<0.05,{ }^{* * *} p<0.01$

satisfaction itself. Other patterns in line with the literature include the U-shaped relationship between age and life satisfaction as well as the positive effect of being married. Most interaction terms are not significant but present the expected signs. Under model 2, health is more important for males, while unemployment seems to affect them less. The ex-ante evaluation of policies in the next section will be based on the results of Model 2. 
Table 2 First stage of 2SLS: health

\begin{tabular}{lll}
\hline & Model 1 & Model 2 \\
\hline Chronic Illness & $-0.360^{* * *}(0.021)$ & $-0.327^{* * *}(0.019)$ \\
Limitation in activities & $-0.523^{* * *}(0.018)$ & $-0.448^{* * *}(0.017)$ \\
Unmet need for treatment & $-0.243^{* * *}(0.028)$ & $-0.163^{* * *}(0.027)$ \\
Unmet need for dental treatment & $-0.251^{* * *}(0.033)$ & $-0.164^{* * *}(0.031)$ \\
Disposable Income (log) & $0.101^{* * *}(0.020)$ & $0.064^{* * *}(0.019)$ \\
Unemployed & $-0.162^{* * *}(0.048)$ & $-0.032(0.046)$ \\
Housing (in 1000SEK) & $0.019^{* *}(0.007)$ & $0.010(0.007)$ \\
Male & $0.021(0.018)$ & $-0.031^{*}(0.018)$ \\
Age & $-0.004(0.003)$ & $-0.005^{*}(0.003)$ \\
Age squared/100 & $-0.004(0.003)$ & $-0.004(0.003)$ \\
Married & $0.067^{* * *}(0.026)$ & $0.051^{* *}(0.024)$ \\
Separated & $-0.007(0.086)$ & $0.084(0.082)$ \\
Divorced & $0.007(0.035)$ & $0.012(0.033)$ \\
Widow & $0.004(0.048)$ & $0.020(0.045)$ \\
Children 0-15 & $-0.001(0.023)$ & $-0.005(0.022)$ \\
Non-Swede & $-0.009(0.046)$ & $0.033(0.044)$ \\
Higher Education & $0.094^{* * *}(0.020)$ & $0.099^{* * *}(0.019)$ \\
South Sweden & $0.043^{* *}(0.020)$ & $0.032^{*}(0.019)$ \\
North Sweden & $0.008(0.027)$ & $-0.015(0.025)$ \\
Down in the dumps & & $-0.099^{* * *}(0.015)$ \\
Calm & & $0.098^{* * *}(0.014)$ \\
Nervous & & $-0.065^{* * *}(0.012)$ \\
Downhearted & $-0.075^{* * *}(0.014)$ \\
cons & $4.130^{* * *}(0.193)$ & $4.506^{* * *}(0.199)$ \\
$N$ & 5336 & 5336 \\
$R^{2}$ & 0.353 & 0.419 \\
\hline & &
\end{tabular}

Standard errors in parentheses

${ }^{*} p<0.10,{ }^{* *} p<0.05,{ }^{* * *} p<0.01$

The estimates of the health regression (Table 2) are also according to expectations. Health indicators such as chronic illness and limitation in activities have a negative effect on selfassessed health, and the same is true for the variables "unmet need". Important for our purposes is the strongly significant effect of income on health, even when we control for education. We will take up this effect in our evaluation of changes in the tax-benefit system in the next section. Note that the quality of housing also has a positive effect on health.

We can now calculate the equivalent incomes. Following the normative reasoning in the previous section, "perfect health" is chosen as the reference value for health and "not being unemployed" as the reference for employment status. Since there is no upper boundary for housing quality, we take the 90th percentile in the sample as the reference value. Based on these reference values, the observations for the relevant life dimensions, and the estimated coefficients in Table 1, equivalent incomes can be computed as in Eq. 7. 
Table 3 Portrait of the deprived

\begin{tabular}{|c|c|c|c|}
\hline & Income & Satisfaction & Eq. Income \\
\hline Income deprived & 1.00 & . & . \\
\hline Satisfaction deprived & 0.16 & 1.00 & . \\
\hline Eq. income deprived & 0.18 & 0.32 & 1.00 \\
\hline Income (SEK/month) & 7,692 & 16,396 & 16,336 \\
\hline Satisfaction & 7.55 & 4.25 & 6.59 \\
\hline Health & 4.06 & 3.26 & 2.66 \\
\hline Unemployment & 0.16 & 0.13 & 0.23 \\
\hline Housing $(1,000$ SEK $)$ & 4.17 & 4.61 & 4.17 \\
\hline Male & 0.49 & 0.44 & 0.73 \\
\hline Age & 37.68 & 50.65 & 54.41 \\
\hline Married & 0.20 & 0.28 & 0.43 \\
\hline Divorced & 0.10 & 0.19 & 0.16 \\
\hline Widow & 0.07 & 0.07 & 0.07 \\
\hline Child 0-15 & 0.28 & 0.19 & 0.15 \\
\hline Non-Swede & 0.12 & 0.06 & 0.06 \\
\hline Higher Education & 0.21 & 0.25 & 0.28 \\
\hline East Sweden & 0.37 & 0.42 & 0.37 \\
\hline South Sweden & 0.46 & 0.42 & 0.41 \\
\hline North Sweden & 0.17 & 0.16 & 0.22 \\
\hline
\end{tabular}

Note: Deprived in terms income, satisfaction and equivalent income are the 383 individuals with the lowest levels of income, life satisfaction and equivalent income, respectively. Income refers to household disposable income equivalised using the OECD modified scale

\subsection{An empirical comparison of the three well-being measures}

The three measures of individual well-being used in this paper (disposable income, life satisfaction and equivalent income) lead to very different results, reflecting their different normative assumptions. This is illustrated by the results in Table 3 , where we concentrate on the characteristics of the most deprived individuals according to each measure. ${ }^{14}$ Here, the most deprived in terms of life satisfaction are defined as those individuals who report a level of life satisfaction equal to 5 or less. The second column of Table 2 presents the characteristics of this group of 383 individuals. The first column presents the same information for the 383 individuals with the lowest equivalized household disposable income. Column 3 shows the information for the 383 individuals with the lowest equivalent income, calculated on the basis of the 2SLS estimates.

The first three rows of the table show the overlap between the three well-being concepts. Only around $16 \%$ of those considered poor according to life satisfaction and $18 \%$ of those considered poor according to equivalent income are among the income poor. In the following rows, we sketch the portrait of the most deprived individuals according to each of the

\footnotetext{
${ }^{14}$ Similar results were shown in Decancq et al. (2015b) with data for Russia.
} 
well-being concepts. These portraits differ substantially. The income-poor attain a reasonably high level of life satisfaction and health. They are on average much younger than the two other groups. By construction, the satisfaction poor and the equivalent income poor have a larger income. The most deprived according to life satisfaction have higher income, better health and better housing and are less likely to be unemployed than those with the lowest values of equivalent income. The importance of the scaling variables (including the idiosyncratic disturbance term) for life satisfaction is well illustrated by a comparison of the income-poor and the satisfaction-poor: the latter do better on all dimensions of life, except health.

\section{Evaluation of counterfactual policy scenarios}

In order to assess the effect of policy reforms on each of our well-being concepts, we simulate four hypothetical policy reforms. As described before, we use EUROMOD to simulate disposable incomes and Eqs. 2-7 to derive the effects on life satisfaction and equivalent incomes. In all counterfactual scenarios, budget neutrality is achieved by an increase in the top tax rate of the government income tax, which is $25 \%$ in Sweden. ${ }^{15}$ The different scenarios are described in detail in Section 4.1. The following subsections discuss the average gains and losses, the resulting inequality in well-being and the effects on social welfare. All results are based on the estimates of Model 2 in Table 1.

\subsection{Description of policy scenarios}

\subsubsection{Counterfactual A: additional social assistance payment}

Social assistance in Sweden is a means-tested benefit aimed at low income families. The benefit unit is the nuclear family, including cohabiting partners and children up to 18 years old, or aged under 20 and receiving the basic child benefit. The conditions to be eligible for social assistance stipulate that the family does not have any wealth and that the family members are willing to work. The benefit amount is calculated as the difference between family needs plus housing costs and family means. Family needs depend on household size, marital status of the parents and the age of the children. The benefit is not taxable. Our first counterfactual scenario (reform A) simulates an additional payment of 4,000 SEK per month (around 400 euros) for those families who are recipients of social assistance.

\subsubsection{Counterfactual B: increase in child benefit amount}

Child benefit in Sweden is a universal benefit for families with children aged 0 to 15 years or less than 20 years if in upper secondary education. The child benefit's basic monthly amount was equal to 1,050 SEK (around 105 euros) in 2013. Children aged 0 to 15 years receive the benefit every month, while children aged 16-20 years receive the basic amount for 10 months out of the year. Additional amounts are paid depending on the number of children in the family. The benefit is not taxable. In our second counterfactual scenario (reform B),

\footnotetext{
${ }^{15}$ Personal income tax in Sweden is divided into four parts: government tax, country council tax, municipality tax and funeral tax. Government income tax in Sweden is assessed individually and it is made up of three bands. The first band is exempted of payment, the rate of the second band is set at $20 \%$, and the rate of the top band is set at $25 \%$.
} 
we simulate an increase in the basic amount of child benefit from 1,050 SEK to 2,000 SEK per month for children aged $0-15$ years.

\subsubsection{Counterfactual C: additional payment of housing allowance for pensioners}

Housing allowance for pensioners is a means-tested benefit targeted at old age pensioners and persons with a disability pension. The assessment unit is the nuclear family, including cohabiting partners and children up to 18 years old, or aged under 20 and receiving the basic child benefit. Individuals aged 65 and above are entitled to the age allowance, while individuals younger than 65 are entitled to the disability allowance. The allowance decreases with income over certain income thresholds, which are dependent on the marital status of the recipients. The benefit is not taxable. In our third counterfactual scenario (reform C), we simulate an additional payment of 2,000 SEK per month (around 200 euros) for the recipients of the housing allowance for pensioners.

\subsubsection{Counterfactual D: improvement in housing quality}

Finally, we simulate a policy reform, which does not involve a monetary transfer and therefore has no positive effect on disposable income. In particular, we simulate an improvement in housing quality of half a standard deviation for the $4 \%$ of individuals in our sample who report low housing quality.

The costs of the various reforms are reflected in the increases in the top government income tax rate, which are necessary to achieve budget neutrality. These are given in the second column of Table 4. ${ }^{16}$ Since all four reform scenarios are assumed to be financed by an increase in government tax, the proportion of people losing (those paying higher taxes) as a result of the reforms equals $4.36 \%$ of our sample in all four cases. Yet the proportions of gainers in the total population are very different for these four scenarios. These are given in the second column of Table 4. The characteristics of these gainers in the base situation, i.e. before the reform, are shown in Table 5. It is striking that reform $\mathrm{C}$ and, even more, reform A, mainly benefit the income-poor in the Swedish society. On the other hand, since low quality housing has an effect on equivalent income (but not on monetary income), those who benefit from reform $\mathrm{D}$ are those with the lowest equivalent incomes.

\subsection{Average gains and effects on inequality}

Ultimately we are interested in the effects of the different policy scenarios on social welfare. These will be discussed in Section 4.3. However, to help interpreting these overall results, we first look at some partial findings. As a first step, the average effects on the recipients of the additional payments or the beneficiaries of the housing improvement are

\footnotetext{
${ }^{16}$ Assessing the cost of reform D is not straightforward since we need information on the likely costs of housing improvements. We assume that the simulated improvement in housing under reform D would require half a month's work for a person employed in construction, plumbing, building finishing and related trades. In 2013, the average salary of a person employed in this sector was 26,900 SEK per month (see Statistics Sweden: http://www.scb.se/en_/Finding-statistics/Statistics-by-subject-area/ Labor-market/Wages-salaries-and-labor-costs/Salary-structures-whole-economy/). Under this assumption, the cost of improving housing quality would be 13,450 SEK per household for the $4 \%$ of our sample that would benefit from such reform. Budget neutrality is then achieved by an increase in the top government tax rate from $25 \%$ to $49.8 \%$.
} 
Table 4 Characteristics of the reform scenarios

\begin{tabular}{lcc}
\hline & New income tax top rate & Proportion of gainers \\
\hline Reform A (social assistance) & 34.8 & $2.98 \%$ \\
Reform B (child benefit) & 45.6 & $13.31 \%$ \\
Reform C (housing allowance) & 33.6 & $6.1 \%$ \\
Reform D (housing quality) & 49.8 & $4 \%$
\end{tabular}

Note: The top tax rate of government income tax in the baseline is $25 \%$ (2013). Gainers are defined as those benefiting from increased payments or housing improvement

given in Table 5. When we consider equivalized household disposable income, reform A (an increase in social assistance) results in the highest average increase for the gainers, followed by reform $\mathrm{C}$ (an increase in housing benefit for pensioners) and reform $\mathrm{B}$ (an increase in child benefit). The improvement of housing quality (reform D) has a slightly negative effect on average disposable income for the beneficiaries, because they do not receive any additional income from the housing reform, while a few of them must pay additional taxes. This latter reform yields the largest proportional gains in terms of life satisfaction and equivalent income, however.

One of the most interesting features of our approach is the possibility of taking into account the cross-effects of changes in the different life dimensions. The importance of these feedback effects can be illustrated for the effects of reform A on equivalent incomes. ${ }^{17}$ Table 5 presents the effects of policy reforms on equivalent income when only the direct effect of income changes is considered (rows EI1 and S1). The table also presents the effects on equivalent income and on life satisfaction when the indirect effect of income changes on health (see Table 2) is taken into account (rows EI2 and S2). Moreover, since the beneficiaries of the additional social assistance payments have small monetary incomes, a large fraction of them reported having unmet needs for medical and/or dental treatment. Given the substantial increase in social assistance that reform A represents $(4,000$ SEK per month), it is natural to assume that (part of) the additional benefits would be used to cover the costs of needed medical and dental treatment. This would again affect health, and hence well-being. The row EI3 in Table 5 shows the equivalent income of gainers when unmet need for medical and dental treatment is assumed to be covered but the indirect effect of income through health is not taken into account. Finally, simulation EI4 combines the two effects and assumes that unmet needs for medical and dental treatment are covered and that there is an effect of income on health. These feedback effects significantly increase equivalent incomes of the beneficiaries of the reform. Of course, this finding must be interpreted cautiously. Raising the income of a person will not immediately improve his/her health. Moreover, unmet needs of medical treatment are not only caused by lack of income; therefore, it is a very strong assumption that they would be fully covered after an income transfer (see, e.g., Schokkaert et al. 2017). Yet, the presence of these positive effects in the longer run is extensively documented in the literature, and neglecting them would certainly lead to an underestimation of the well-being gains for the concerned groups. These simulation results illustrate that interesting and important questions come to the fore and can in principle be tackled when one moves to a richer evaluative framework.

\footnotetext{
${ }^{17}$ A similar story can be told for the effects on life satisfaction.
} 
Table 5 Average values under the baseline and counterfactual scenarios for beneficiaries

Base A Reform A Base B Reform B Base C Reform C Base D Reform D

\begin{tabular}{lllllllll}
\hline Disposable income & 8,830 & 12,576 & 19,699 & 20,144 & 11,682 & 13,682 & 13,035 & 13,002 \\
Equivalent income (EI1) & 570 & 784 & 4,970 & 5,039 & 305 & 363 & 133 & 280 \\
Equivalent income (EI2) & 570 & 861 & 4,970 & 5,064 & 305 & 381 & 133 & 332 \\
Equivalent income (EI3) & 570 & 823 & - & - & - & - & - & - \\
Equivalent income (EI4) & 570 & 904 & - & - & - & - & - & - \\
Life satisfaction (S1) & 6.7938 & 6.8221 & 7.9505 & 7.9534 & 7.4455 & 7.4579 & 7.4875 & 7.5446 \\
Life satisfaction (S2) & 6.7938 & 6.8302 & 7.9505 & 7.9542 & 7.4455 & 7.4614 & 7.4875 & 7.5580 \\
Life satisfaction (S3) & 6.7938 & 6.8085 & - & - & - & - & - & - \\
Life satisfaction (S4) & 6.7938 & 6.8449 & - & - & - & - & - & - \\
\hline
\end{tabular}

Note: Disposable income refers to household disposable income equivalised using the OECD modified scale. E1 and S1: only direct effect of income considered. E2 and S2: indirect effect of income changes on health considered. E3 and S3: only direct effect of income considered and unmet medical/dental needs assumed covered. E4 and S4: indirect effect of income changes on health considered and unmet medical/dental needs assumed covered

We now broaden our scope to assess the effects of the reforms over the whole population. Table 6 presents the overall averages for the three well-being concepts under the baseline and for each of the counterfactual scenarios. We take into account the effect of changes in income and housing quality on health, but we disregard the potential link through unmet needs. ${ }^{18}$ Average life satisfaction for the whole sample increases the most under reform $\mathrm{D}$, followed by reforms A, C and B. The effects on average disposable income are negative for reform B and (as expected) D. With equivalent incomes, all reforms have a negative effect on the global average, and the strongest negative effect is found for reform $\mathrm{D}$, despite the fact that the improvement of housing quality increases the equivalent income of the beneficiaries. This result is explained by the different cardinalization of the well-being measures: the equivalent income is linear in actual income (see Eq. 7), while income has a decreasing marginal effect on life satisfaction (because of the logarithmic specification of Eq. 5). With (equivalent) incomes, inequality aversion should be seen as a normative value that is reflected in the choice of the social welfare function. We will return to this issue in the next section.

Finally, the bottom half of Table 6 shows the effect of the reforms on the Gini coefficient. ${ }^{19}$ These results are to some extent the mirror image of those for the averages. The effects of the reforms on satisfaction inequality are very small compared to those on income inequality. For equivalent income, the effect of the reforms is larger than for life satisfaction but still much lower than for disposable income. Equivalent income inequality decreases the most under reform D, followed by reforms B, A and C. The Gini coefficients for disposable decrease by more than $3 \%$ under all reforms. Reform B decreases inequality the most, followed by reforms $\mathrm{A}, \mathrm{D}$ and $\mathrm{C}$, but the differences are not very large.

\footnotetext{
${ }^{18}$ More detailed results can be found in the Online Appendix.

${ }^{19}$ Table 13 in the Online Appendix also presents results for a generalized Gini with parameter of inequality aversion, $\rho=5$, which gives more weight to individuals at the bottom of the income distribution.
} 
Table 6 Average values and inequality under the baseline and counterfactual scenarios

\begin{tabular}{llllll}
\hline & Base & Reform A & Reform B & Reform C & Reform D \\
\hline AVERAGES & & & & \\
Disposable income & 20,184 & 20,186 & 20,145 & 20,215 & 19,909 \\
Equivalent income (EI2) & 4,515 & 4,463 & 4,444 & 4,466 & 4,368 \\
Life satisfaction (S2) & 7.9428 & 7.9436 & 7.9433 & 7.9436 & 7.9449 \\
GINI-COEFFICIENT & & & & & 0.2364 \\
Disposable income & 0.2447 & 0.2356 & 0.2355 & 0.8139 & 0.8106 \\
Equivalent income (EI2) & 0.8159 & 0.8135 & 0.8113 & 0.0643 & 0.0643 \\
Life satisfaction (S2) & 0.0644 & 0.0643 & 0.0644 & & \\
\hline
\end{tabular}

Note: Disposable income refers to household disposable income equivalised using the OECD modified scale. E2 and S2: indirect effect of income changes on health considered

\subsection{Social welfare}

To evaluate the effects of the counterfactual reforms on overall social welfare, we have to consider both the results for the average level and for inequality. For that purpose we calculate social welfare as

$$
S W \rho=A\left(1-I_{\rho}\right),
$$

where $A$ is average well-being and $I_{\rho}$ is the Generalized Gini for inequality aversion $\rho$. For $\rho=0$ we get $I_{\rho}=0$, and hence social welfare reduces to the (unweighted) global average of well-being that was given in Table 6 . The welfare rankings of the policy reforms for the different concepts of well-being and for two values of $\rho$ are shown in Table $7 .^{20}$ For $\rho=2$, inequality is measured by the Gini-coefficient (as in Table 6). A value of $\rho=5$ implies that we give a larger weight to the well-being of persons at the bottom of the well-being distribution. The results in Table 7 allow us to draw some important lessons.

First, the ranking of policy reforms depends crucially on two normative choices: the measure of individual well-being and the degree of inequality aversion. Focusing only on disposable income may be very misleading if society prefers a broader concept of wellbeing, be it life satisfaction or equivalent income.

Second, since all our policy measures reduce inequality, more policies become welfareimproving, compared to the base, if the inequality aversion in the social welfare function increases. This is most striking for equivalent incomes, where all policies decrease welfare for $\rho=0$, but increase welfare for $\rho=5$. For life satisfaction, all policies are already welfare improving for $\rho=0$. In fact, increasing inequality aversion does not change the ranking of the policies if we take life satisfaction as the relevant well-being concept. As mentioned before, equivalent income is linear in disposable income. Monetary income transfers may have welfare effects due to differences in preferences and the levels of the other life dimensions (see Eq. 7), but these effects will be rather small. If one cares about well-being inequality this must be taken up in the normative inequality aversion - with a positive inequality aversion, an income transfer from someone with a high level of equivalent income to someone with a low level of equivalent income will increase social welfare. This is what we observe in Table 7: as soon as $\rho$ starts increasing, more inequality reducing policies also become welfare improving. The situation is different if we take subjective

\footnotetext{
${ }^{20}$ Table 14 in the Online Appendix presents the detailed results for (9) for all the policy scenarios.
} 
Table 7 Ranking of policies

\begin{tabular}{lllllllll}
\hline \multicolumn{2}{c}{ disposable income } & \multicolumn{3}{c}{ life satisfaction (S2) } & \multicolumn{3}{c}{ equivalent income (EI2) } \\
$\rho=0$ & $\rho=2$ & $\rho=5$ & $\rho=0$ & $\rho=2$ & $\rho=5$ & $\rho=0$ & $\rho=2$ & $\rho=5$ \\
\hline C & C & A & D & D & D & base & B & D \\
A & A & C & A & A & A & C & A & B \\
base & B & B & C & C & C & A & base & A \\
B & base & base & B & B & B & B & C & C \\
D & D & D & base & base & base & D & D & base \\
\hline
\end{tabular}

Policies ranked in decreasing order of social welfare. Disposable income refers to household disposable income equivalised using the OECD modified scale. E2 and S2: indirect effect of income changes on health considered

life satisfaction as a measure of well-being. This cardinalization implies declining marginal utility of income and it is well known that if this is the case, income transfers from rich to poor are welfare-increasing, even in the (utilitarian) case $\rho=0$.

Third, implementing a richer well-being framework makes it possible to evaluate nonincome policies. A policy aiming to improve the housing quality of the poor (our reform D) can never be welfare-improving if one only considers disposable income, because in that narrow setting there are only costs and no benefits. It is preferred over all the income transfer policies, however, if we evaluate well-being in terms of life satisfaction or in terms of equivalent income with a sufficiently large degree of inequality aversion.

\section{Conclusion}

Microsimulation is the preferred method for the ex-ante evaluation of policy scenarios. Until now applications have mostly been restricted to the simulation of disposable incomes. This goes against the widespread conviction that other non-material life dimensions also matter for individual well-being. We have shown that in principle it is easy to perform a microsimulation analysis within a richer evaluative framework. This requires simulation of the effects of a policy on other life dimensions, and for many of these effects there is already substantial empirical evidence. Aggregating the different dimensions into one scalar measure of individual well-being requires making ethical choices. However neglecting these genuine and important normative questions leads to an undesirable impoverishment of the policy debate. Taking life satisfaction as the relevant measure of individual well-being is a natural choice, but it raises the issue as to whether, for a distributional analysis, we should accept that individuals are compensated when they are less satisfied due to having higher expectations or are less compensated for misfortune if they more easily adapt to their new situation. If the response to these questions is negative, one must look for an alternative measure of individual well-being. We proposed the equivalent income measure as a possible candidate. Our empirical application for Sweden illustrates the importance of this choice. In particular, individuals with the lowest levels of life satisfaction have on average a higher income and better health, and are less likely to be unemployed than those deprived in terms of equivalent incomes.

We then simulated the effects of four hypothetical policy reforms using the three measures of well-being (disposable income, life satisfaction and equivalent income). The 
simulation results confirm that the choice of well-being measure is important for the welfare ranking of policies. An important aspect of this is that implementing a richer evaluative framework makes it possible to also analyze the effects of non-monetary policy reforms, and to compare the welfare effects of such reforms with those of tax-benefit policies. Moreover, feedback effects between the different life dimensions are important and can easily be taken into account. This was illustrated for the (well-known) relationship between health (care) and income. This paper presents a simple illustration of how microsimulation techniques can be used to evaluate policy reforms in terms of individual well-being. It also shows how microsimulation models can contribute to a better understanding of the links between economic thinking, ethical values and applied policy making (Atkinson 2009).

Our empirical work has some obvious shortcomings. Ideally, one would estimate a full model involving all the interactions between the relevant dimensions of life. Future research would, in particular, benefit from the availability of panel data, allowing one to account for the long-term relationship between a broad range of life dimensions. Moreover, for equivalent incomes, the identification of preferences on the basis of a life satisfaction equation is only a first step (see Decancq et al. 2015b for a more extensive discussion). The identification of preferences could, for instance, be improved by the inclusion of information on stated preferences in surveys. More work is needed to correct these shortcomings. Yet, the direction this work should take is clear. Given the obvious limitations of focusing only on disposable incomes, it seems important to start walking that route.

Acknowledgments This research was supported by the NORFACE ERA-NET (New Opportunities for Research Funding Agency Co-operation in Europe Network) Welfare State Futures Program, Grant Number 462-14-010. The results presented here are based on EUROMOD version G2.35. EUROMOD is maintained, developed and managed by the Institute for Social and Economic Research (ISER) at the University of Essex, in collaboration with national teams from the EU member states. We are indebted to the many people who have contributed to the development of EUROMOD. The process of extending and updating EUROMOD is financially supported by the European Union Program for Employment and Social Innovation 'Easi' (20142020). We make use of microdata from the EU Statistics on Incomes and Living Conditions (EU - SILC) made available by Eurostat (59/2013 - EU - SILC - LFS). The results and their interpretation are the authors' responsibility. We thank the editor and an anonymous referee for their useful comments.

Open Access This article is distributed under the terms of the Creative Commons Attribution 4.0 International License (http://creativecommons.org/licenses/by/4.0/), which permits unrestricted use, distribution, and reproduction in any medium, provided you give appropriate credit to the original author(s) and the source, provide a link to the Creative Commons license, and indicate if changes were made.

\section{References}

Aaberge, R., Brandolini, A.: Multidimensional poverty and inequality. In: Atkinson, A., Bourguignon, F. (eds.). Handbook of Income Distribution, vol. 2A, pp. 141-216. Elsevier, New York (2015)

Atkinson, A.: Multidimensional deprivation: contrasting social welfare and counting approaches. J. Econ. Inequal. 1, 51-65 (2003)

Atkinson, A.: An enlarged role for tax-benefit models. In: Lelkes, O., Sutherland, H. (eds.) Tax and Benefit Policies in the Enlarged Europe: Assessing the Impact withMicrosimulationModels, pp. 3346. Vienna, Ashgate (2009)

Atkinson, A.: The restoration of welfare economics. Am. Econ. Rev. Pap. Proc. 101, 157-161 (2011)

Atkinson, A., Bourguignon, F.: The comparison of multi-dimensioned distributions of economic status. Rev. Econ. Stud. 49, 183-201 (1982)

Atkinson, A., King, M., Sutherland, H.: The analysis of personal taxation and social security. Natl. Inst. Econ. Rev. 103, 63-74 (1983) 
Atkinson, A., Cantillon, B., Marlier, E., Nolan, B.: Social Indicators. The EU and Social Inclusion. Oxford University Press, Oxford (2002)

Bargain, O., Decoster, A., Dolls, M., Neumann, D., Peichl, A., Siegloch, S.: Welfare, labor supply and heterogeneous preferences: evidence for Europe and the US. Soc. Choice Welf. 41, 789-817 (2013)

Bruno, M.-A., Bernheim, J., Ledoux, D., Pellas, F., Demertzi, A., Laureys, S.: A survey on self-assessed wellbeing in a cohort of chronic locked-in syndrome patients: happy majority, miserable minority. British Medical Journal Open (2011). https://doi.org/10.1136/bmjopen-2010-000039

Decancq, K., Fleurbaey, M., Schokkaert, E.: Inequality, income and well-being. In: Atkinson, A., Bourguignon, F. (eds.). Handbook of Income Distribution, vol. 2A, pp. 67-140. Elsevier, New York (2015a)

Decancq, K., Fleurbaey, M., Schokkaert, E.: Happiness, equivalent income and respect for individual preferences. Economica 82, 1082-106 (2015b)

Decancq, K., Schokkaert, E., Zuluaga, B.: Implementing the capability approach with respect for individual valuations: an illustration with Colombian data. Department of Economics, KU Leuven: DPS 2016.09 (2016)

Decancq, K., Fleurbaey, M., Schokkaert, E.: Well-being inequality and preference heterogeneity. Economica 84, 210-238 (2017)

Decoster, A., Haan, P.: Empirical welfare analysis with preference heterogeneity. Int. Tax Publ. Financ. 22, 224-51 (2015)

Ferrer-i-Carbonell, A., Frijters, P.: How important is methodology for the estimates of the determinants of happiness? Econ. J. 114, 641-59 (2004)

Fleurbaey, M., Maniquet, F.: A Theory of Fairness and Social Welfare. Cambridge University Press, Cambridge (2011)

Fleurbaey, M., Blanchet, D.: Beyond GDP. Measuring Welfare and Assessing Sustainability. Oxford University Press, Oxford (2013)

Fleurbaey, M., Luchini, S., Muller, C., Schokkaert, E.: Equivalent income and the economic evaluation of health care. Health Econ. 22, 711-29 (2013)

Layard, R.: Happiness: Lessons from a New Science. Allan Lane, London (2005)

Loewenstein, G., Ubel, P.: Hedonic adaptation and the role of decision and experienced utility in public policy. J. Publ. Econ. 92, 1795-810 (2008)

Nussbaum, M.: Women and Human Development: the Capabilities Approach. Cambridge University Press, Cambridge (2000)

O’Donnell, G., Oswald, A.: National well-being policy and a weighted approach to human feelings. Ecol. Econ. 120, 59-70 (2015)

Schokkaert, E., Van Ootegem, L., Verhofstadt, E.: Preferences and subjective job satisfaction: measuring well-being on the job for policy evaluation. CESifo Econ. Stud. 57(4), 683-714 (2011)

Schokkaert, E., Van de Voorde, C., Dormont, B., Fleurbaey, M., Luchini, S., Samson, A.-L., Thébaut, C.: Equity in health and equivalent incomes. In: Rosa Dias, P., O’Donnell, O. (eds.) Health and Inequality (Research on Economic Inequality, Volume 21), pp. 131-56, Bingley, Emerald (2013)

Schokkaert, E., Steel, J., Van de Voorde, C.: Out-of-pocket payments and subjective unmet need of health care. Appl. Health Econ. Health Policy 15, 545-555 (2017)

Sen, A.: Commodities and Capabilities. North-Holland, Amsterdam (1985)

Stiglitz, J., Sen, A., Fitoussi, J.-P.: Report by the Commission on the Measurement of Economic Performance and Social Progress. Paris (2009)

Sutherland, H., Figari, F.: EUROMOD: The European Union tax-benefit microsimulation model. Int. J. Microsimul. 6, 4-26 (2013) 